\title{
CARACTERÍSTICAS DA SUPERFÍCIE E DA FENDA IMPLANTE-INTERMEDIÁRIO EM SISTEMAS DE DOIS E UM ESTÁGIOS
}

\author{
CHARACTERISTICS OF IMPLANT SURFACE AND IMPLANT-ABUTMENT GAP \\ IN TWO- AND ONE-STAGE SYSTEMS
}

\section{Julio Cesar JOLY}

Doutor em Clínica Odontológica na Área de Periodontia da Faculdade de Odontologia de Piracicaba da Universidade Estadual de Campinas.

Antonio Fernando Martorelli de LIMA

Professor Titular da Área de Periodontia da Faculdade de Odontologia de Piracicaba da Universidade Estadual de Campinas.

\begin{abstract}
P bjetivo deste estudo foi avaliar em microscopia eletrônica de varredura as características da superfície e da fenda existente entre os componentes de implantes de dois e um estágios. Foram selecionados 3 implantes de dois estágios revestidos com fosfato de cálcio cerâmico (RBM) e 3 implantes de um estágio revestidos com plasma de titânio (TPS). Nos implantes de dois estágios, os intermediários tipo esthetic-cone foram adaptados ao hexágono externo e travados com parafuso com torque definitivo de $20 \mathrm{~N} / \mathrm{cm}$. Nos implantes de um estágio foram utilizados intermediários sólidos que foram adaptados e fixados por travamento friccional com torque definitivo de $30 \mathrm{~N} / \mathrm{cm}$. Os espécimes foram montados em stubs e analisados em microscopia eletrônica de varredura. A fenda foi medida em quatro pontos com três repetições em cada implante. Os valores obtidos foram avaliados pelo teste t pareado de Student. Os resultados mostraram que não houve diferença estatística significativa $(P>0,05)$ na extensão da fenda entre os sistemas de um e dois estágios e que os tratamentos proporcionaram diferentes características de superfície.
\end{abstract}

UNITERMOS: Implante dentário endósseo.

\section{INTRODUÇÃO}

O desenvolvimento dos implantes dentais revolucionou as possibilidades de reabilitação para pacientes parcial ou totalmente desdentados. Diversos estudos longitudinais têm mostrado altas taxas de sucesso com a utilização dessa opção terapêutica ${ }^{1,2,3,4}$.

A osseointegração requer a utilização de implantes confeccionados com material e superfície atrativas à deposição óssea. O titânio comercialmente puro é o material de escolha para a confecção dos implantes endósseos, pois é um metal que possibilita reação tecidual favorável, estabilidade química dos componentes, estimula a atividade celular na formação da matriz óssea, tem elevada resistência à corrosão e não provoca reações de hipersensibilidade ou imunológicas ${ }^{5}$. A camada de óxido de titânio é responsável pela adaptação íntima - denominada osseointegração ou anquilose funcional - entre o osso mineralizado e a superfície do implante ${ }^{6,7}$.
A busca por uma configuração adequada levou ao aparecimento dos implantes cilíndricos rosqueáveis, que proporcionavam grande área de contato, estabilidade e transferência de cargas ${ }^{8.9}$. Existem diversos tipos de tratamento para tornar rugosa a superfície torneada dos implantes ${ }^{10,11}$. Dentre os tratamentos, podemos destacar o ataque ácido, o jateamento com partículas e a associação de ambos os métodos ${ }^{12}$.

$\mathrm{O}$ aumento da rugosidade, as características físicoquímicas e as propriedades do material influenciam a retenção mecânica inicial dos implantes e aumenta a área de contato com o leito ósseo receptor favorecendo a osseointegração.

Os implantes endósseos foram originalmente desenhados para serem recobertos pelo retalho, necessitando, portanto, de um segundo estágio cirúrgico para a exposição e colocação dos componentes secundários. Essa conexão produz o aparecimento de duas fendas entre os componentes ${ }^{13,14}$.

A osseointegração também pode ser alcançada com 
a utilização de implantes de um estágio ${ }^{15}$, cuja porção transmucosa é um prolongamento da porção endóssea, eliminando o segundo procedimento cirúrgico. Nestes implantes haverá somente uma fenda localizada entre o corpo do implante e a conexão protética ${ }^{16}$.

O objetivo deste estudo foi avaliar em microscopia eletrônica de varredura, as características da superfície, a extensão e a localização das fendas implanteintermediário nos sistemas de dois e um estágios.

\section{MATERIAIS E MÉTODOS}

Foram selecionados 3 implantes de dois estágios revestidos com fosfato de cálcio cerâmico - RBM (Restore - Lifecore Biomedical, Chaska, MN, USA) e 3 implantes de um estágio revestidos com plasma de titânio - TPS (Stage 1 - Lifecore Biomedical, Chaska, MN, USA). Os intermediários foram colocados seguindo as recomendações do fabricante. Para tanto, os implantes foram fixados em morsa com mordentes revestidos por borracha esterilizada. Os intermediários tipo esthetic-cone (RD conical abutment - Lifecore Biomedical, Chaska, MN, USA) foram adaptados ao hexágono externo do implante de dois estágios e travados com parafuso com torque definitivo de 20 $\mathrm{N} / \mathrm{cm}$. No sistema de um estágio foi utilizado intermediário sólido (COC abutment - Lifecore Biomedical, Chaska, MN, USA) que foi adaptado e fixado ao corpo do implante por travamento friccional tipo cone morse de $8^{\circ}$ com torque definitivo de $30 \mathrm{~N} /$ $\mathrm{cm}$. Foram utilizados torquímetros específicos para cada sistema. Todos os intermediários foram colocados na mesma sessão laboratorial e o conjunto foi mantido em temperatura e umidade ambiente (Figura 1).

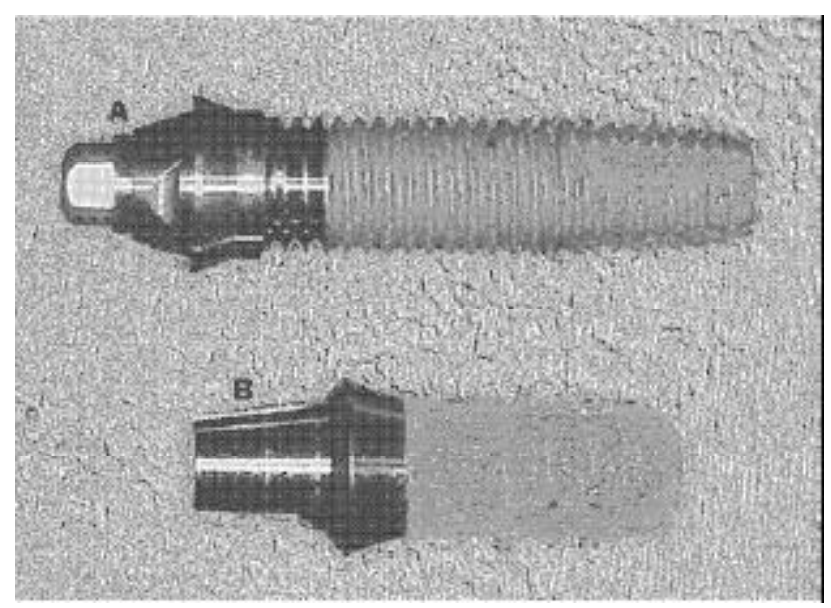

FIGURA 1- Aspecto macroscópico dos implantes e dos intermediários nos sistemas de dois $(A)$ e um $(B)$ estágios
Os espécimes foram montados em suportes apropriados e analisados em microscopia eletrônica de varredura (JEOL 5600 LV, Japan) com voltagem de $15 \mathrm{kV}$. Para a observação da fenda, os espécimes do sistema de dois estágios foram posicionados somente no sentido longitudinal, enquanto que os do sistema de um estágio foram posicionados nos sentidos longitudinal e transversal.

A extensão das fendas foi medida com a utilização de duas barras paralelas do próprio microscópio, em aumento de 1500 vezes em 4 pontos equiidistantes ao redor da superfície do conjunto implanteintermediário. As medidas foram repetidas 3 vezes em cada conjunto e transformadas em média aritmética. Os valores obtidos foram avaliados pelo teste $\mathrm{t}$ pareado de Student considerando o nível de significância a = 0,05 .

\section{RESULTADOS}

As Figuras 2 a 5 mostram o limite entre as porções rugosa e lisa dos dois sistemas. A aplicação do revestimento com fosfato de cálcio cerâmico é feita a partir da terceira rosca do implante, ocupando a maior parte, mas não toda a extensão endóssea (Figura 2), e provoca a dissipação de resíduos em direção ao vale entre a segunda e terceira roscas (Figura 4). O jateamento com plasma de titânio cobre toda a extensão da porção endóssea (Figura 3), mas não cria uma separação nítida entre as porções rugosa e lisa. $\mathrm{Na}$ área do transmucoso, os resíduos aparecem como pequenos riscos que se estendem em direção ao ombro do implante em até $300 \mu \mathrm{m}$ do limite endósseo (Figura $5)$.

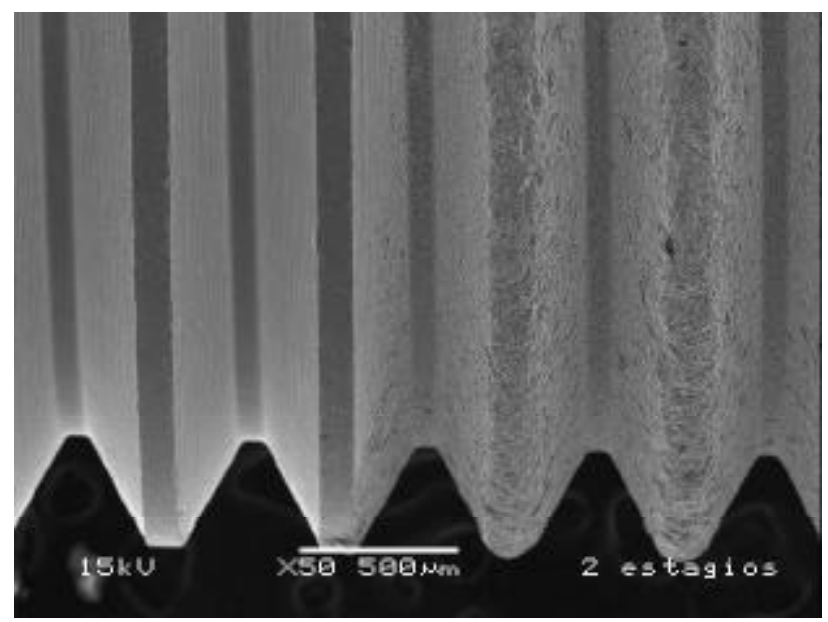

FIGURA 2- Porção rugosa e lisa nos implantes de dois estágios. Observar a presença do RBM a partir da terceira rosca (seta) $(x 50)$ 


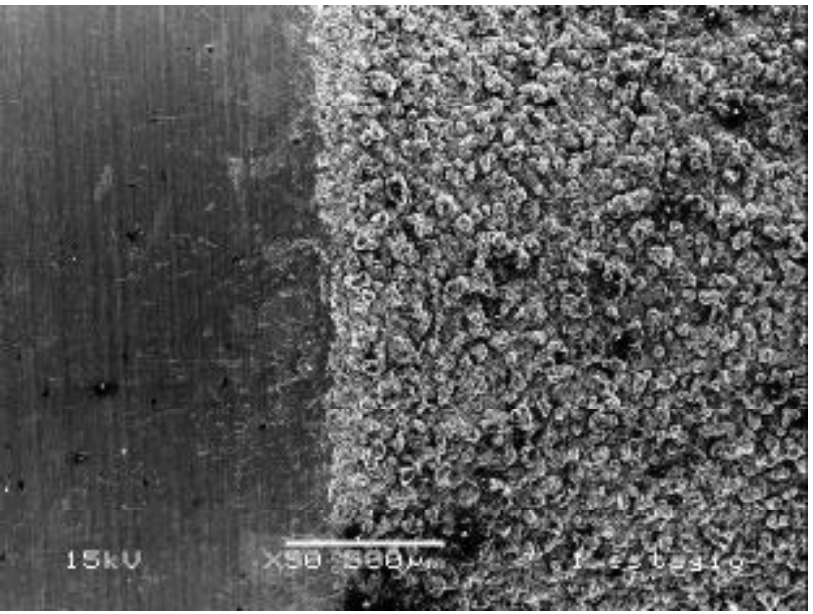

FIGURA 3- Porção rugosa e transmucoso polido nos implantes de um estágio. Observar a presença do TPS em toda porção endóssea (seta) (x50)

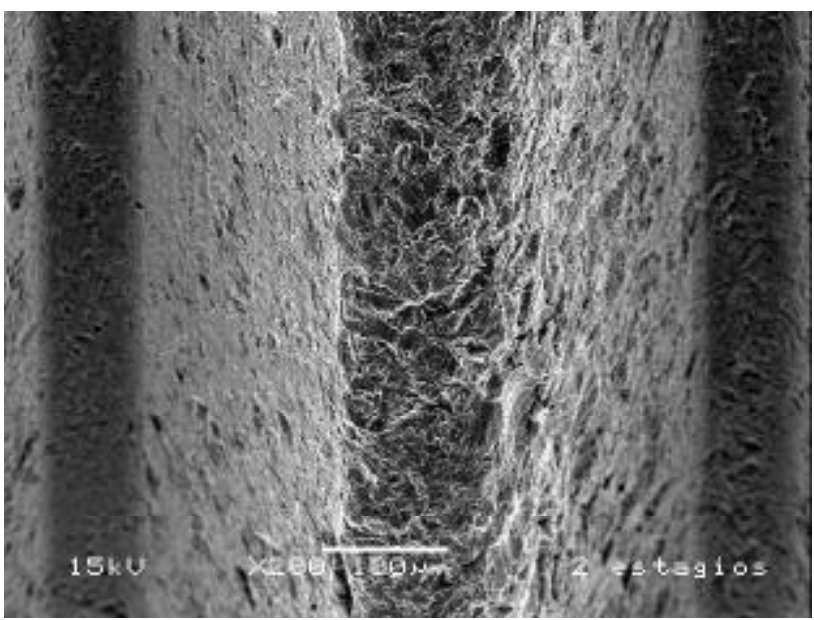

FIGURA 4- Limite entre a porção rugosa e lisa. Observar a dissipação de resíduos (seta) (x200)

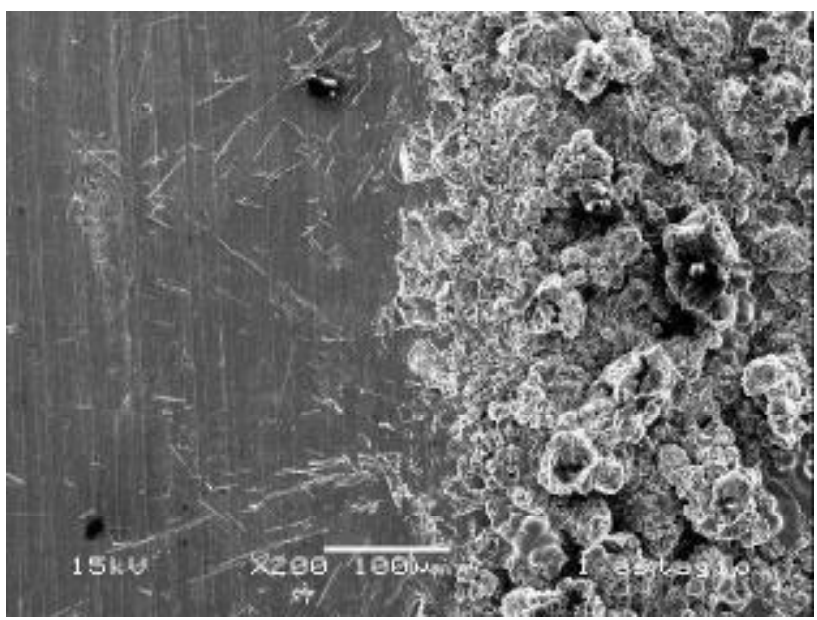

FIGURA 5- Limite entre a porção rugosa e transmucoso polido. Observar a dissipação de resíduos (seta) (x200)
As Figuras 6 e 7 mostram as características das superfícies revestidas com jateamento de fosfato de cálcio - RBM (Figura 6) e jateamento de plasma de titânio - TPS (Figura 7). Na Figura 6 é possível observar a presença de partículas pequenas e uniformes entre $5 \mu \mathrm{m}$ e $10 \mu \mathrm{m}$, enquanto que na Figura 7 as partículas são maiores e desiguais, medindo entre 20 $\mu \mathrm{m}$ e $30 \mu \mathrm{m}$.

As Figuras 8 a 13 mostram as fendas da interface implante-intermediário. Nos implantes de dois estágios, o intermediário é justaposto ao implante e fixado por parafuso criando uma fenda externa (Figuras 8 e 10). Nos implantes de um estágio, o intermediário é retido por fricção mecânica, a fenda interna ficará vedada pelo cimento de fixação da prótese e distante do ombro do implante (Figuras 9 e 11). As setas indicam a localização da fenda nos diversos aumentos analisados.

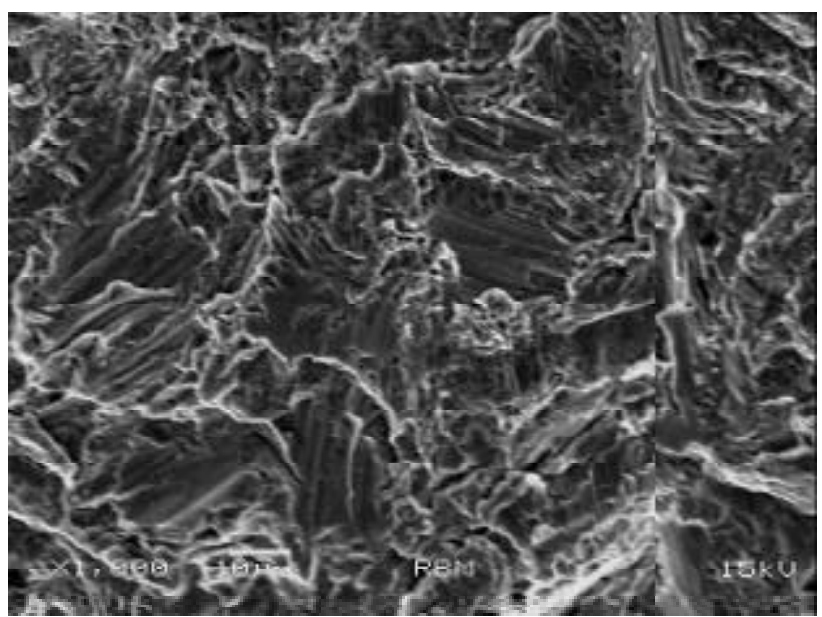

FIGURA 6- Superfície revestida por RBM. Observar distribuição homogênea das partículas pequenas (x1000)

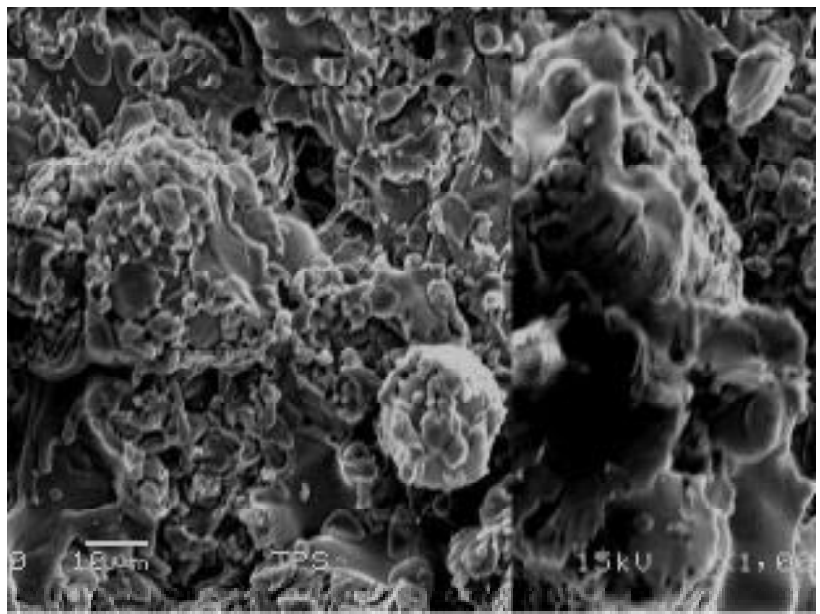

FIGURA 7- Superfície revestida por TPS. Observar distribuição desigual de partículas maiores (x1000) 


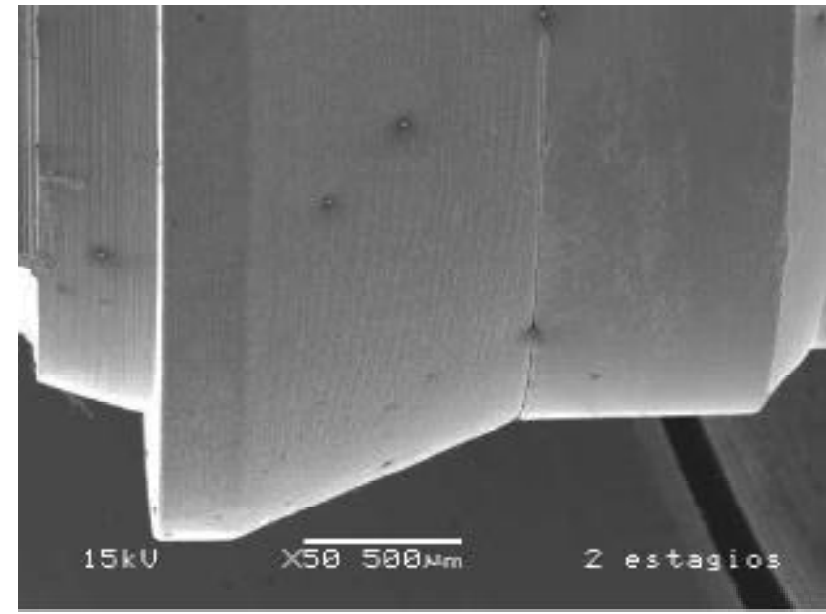

FIGURA 8- Localização da fenda no sistema de dois estágios (seta). Observar a presença de único plano (x50)

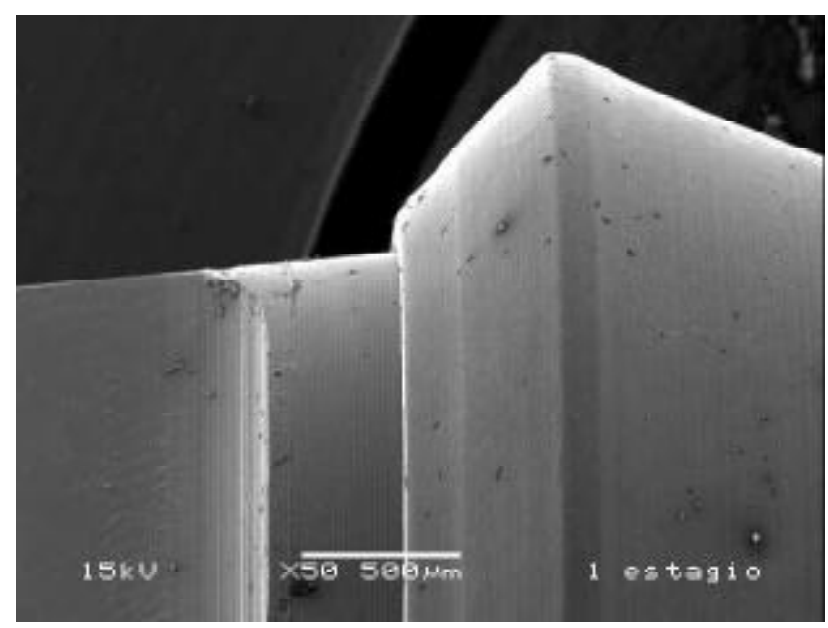

FIGURA 9- Localização da fenda no sistema de um estágio (seta). Observar a presença de dois planos (50xs)

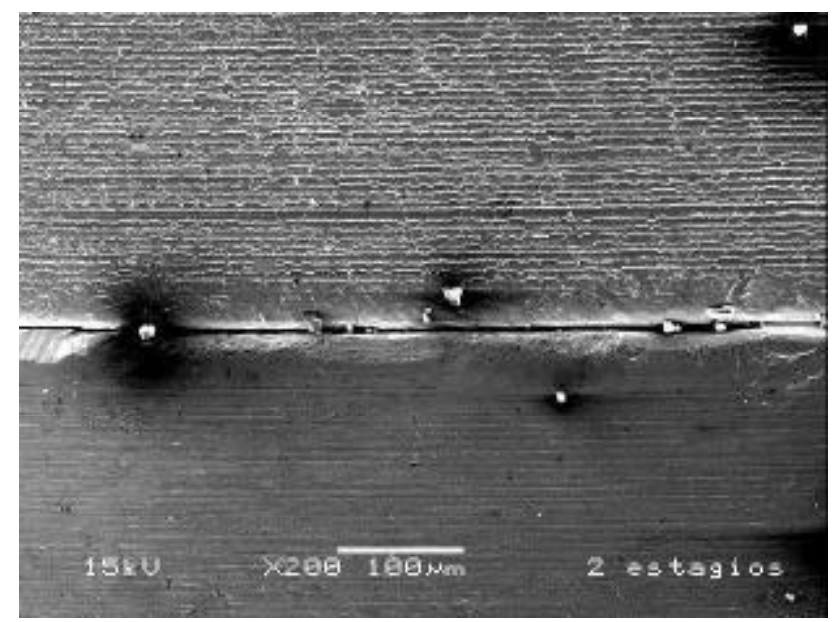

FIGURA 10- Observação da fenda (seta) no sentido 110

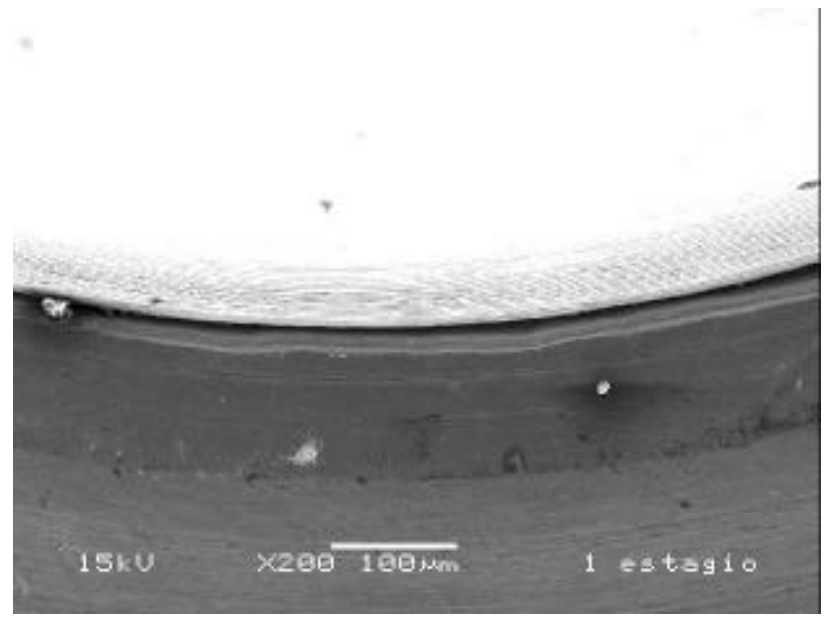

FIGURA 11- Observação da fenda (seta) no sentido transversal no sistema de um estágio (x200)

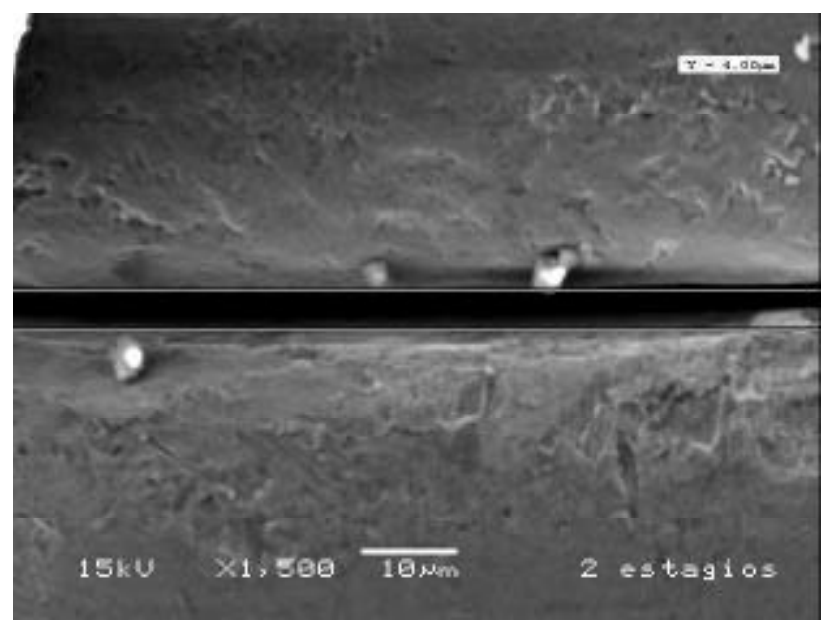

FIGURA 12- Determinação da extensão da fenda (seta) no sistema de dois estágios (x1500)

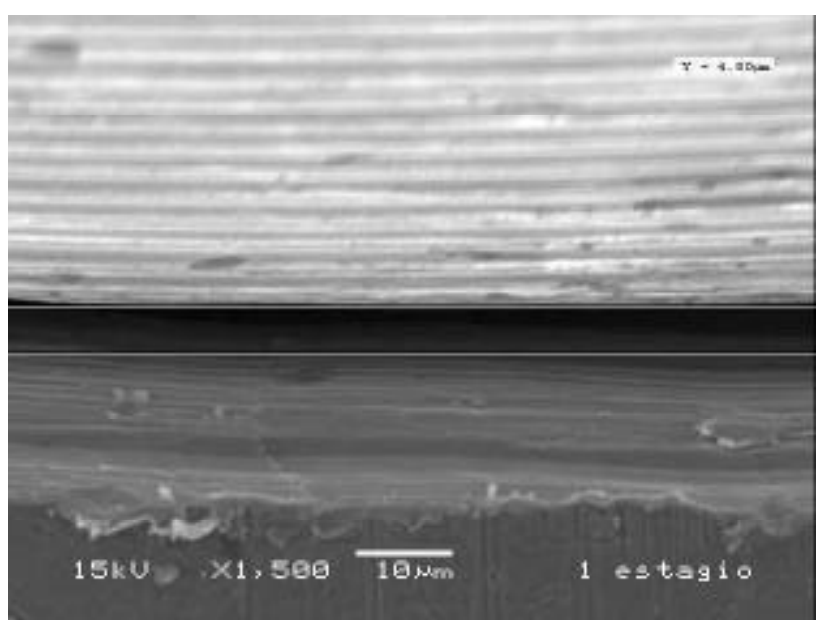

FIGURA 13- Determinação da extensão da fenda (seta) no sistema de um estágio (x1500) 
A extensão média da fenda foi calculada nas imagens com aumento de 1500 vezes. Nos implantes de 2 estágios (Figura 12) a fenda foi de 3,89 $\pm 0,36$ $\mu \mathrm{m}$ e nos implantes de 1 estágio (Figura 13) foi de $3,98 \pm 1,29 \mu \mathrm{m}$. Não houve diferença estatística significativa $(\mathrm{P}>0,05)$ entre os sistemas (Tabela 1$)$.

TABELA 1- Extensão da fenda (em $\mu \mathrm{m})$

\begin{tabular}{llll}
\hline & 2 estágios & 1 estágio & $P$ \\
\hline fenda & $3,89 \pm 0,36$ & $3,98 \pm 1,29$ & 0,4264 \\
\hline
\end{tabular}

Teste $\mathrm{t}$ pareado de Student; nível de significância $=\mathrm{P}<0,05$

\section{DISCUSSÃO}

O conceito de osseointegração tem sido explicado como sendo a união estrutural e funcional entre o osso vivo e organizado e a superfície de um implante submetido ao carregamento protético ${ }^{17}$. Esse fenômeno pode ser influenciado pelas características da superfície do implante. A rugosidade representa uma modificação micromorfológica estrutural que aumenta a área de contato entre o osso mineralizado e o implante ${ }^{7,18}$. Carlsson, et al. ${ }^{19}$ e Carr, et al. ${ }^{20}$ demonstraram que a superfície rugosa aumenta a resistência ao torque de remoção e favorece a deposição óssea quando comparada à superfície lisa.

A aplicação de ácidos, entre eles os hidroclorídrico, sulfúrico, hidrofluorídrico e nítrico, cria micro cavitações na superfície torneada, que variam de acordo com o tipo, concentração e temperatura do ácido empregado. Entretanto, o ataque ácido pode produzir superfície rugosa não apropriada e afetar a resistência do material à fadiga ${ }^{10}$. A modificação da superfície do implante com o jateamento de partículas é capaz de promover rugosidade semi-porosa que favorece uma forte ancoragem óssea quando comparada às superfícies torneadas ou tratadas com ácido. $\mathrm{O}$ jateamento pode ser conseguido com plasma de titânio ${ }^{21}$ ou materiais aloplásticos como o fosfato de cálcio cerâmico que é compatível e pode ser reabsorvido ${ }^{22}$. A associação do jateamento de partículas com o ataque ácido também é capaz de criar rugosidade significativa.

Na Figura 2 é possível notar que, nos implantes de dois estágios, o tratamento superficial inicia na terceira rosca e atinge a depressão entre a segunda e terceira rosca. Não existe um limite nítido separando a área tratada e não tratada (Figura 4). Segundo o fabricante, esse tratamento não deve atingir as primeiras roscas dos implantes, porque normalmente essa região será envolvida pela reabsorção óssea inicial.

Nos implantes de um estágio, é possível notar a união entre a porção endóssea e a transmucosa (Figura 3). Não existe uma linha uniforme separando as duas superfícies. O jateamento com TPS recobre toda a porção endóssea, entretanto, produz irregularidades na porção polida do transmucoso (Figura 5). Nesse sistema o tratamento de superfície atinge toda a porção endóssea.

O tamanho da partícula, a pressão e a duração do procedimento de jateamento interferem na rugosidade superficial. Estudos mostraram que para a melhor deposição óssea, o tamanho das partículas de jateamento deve variar entre $25 \mu \mathrm{m}$ e $75 \mu \mathrm{m}^{10,12}$.

A Figura 6 mostra a superfície tratada com fosfato de cálcio (RBM) que produziu rugosidade uniforme em toda extensão, com partículas variando entre $5 \mu \mathrm{m}$ e $10 \mu \mathrm{m}$. A Figura 7 mostra o tratamento de superfície com jateamento de plasma de titânio (TPS). Podemos observar microporos extensos e irregulares (entre 20 $\mu \mathrm{m}$ e $30 \mu \mathrm{m}$ ) que conferem grande rugosidade. A interpretação dos nossos resultados sugere que ambos tratamentos produzem superfícies rugosas, favoráveis ao aumento da área de contato osso mineralizadoimplante.

Os implantes endósseos convencionais devem ser recobertos pelo retalho para evitar contaminação e exigem um segundo procedimento cirúrgico para a exposição do ombro do implante e colocação dos componentes protéticos. Entretanto, a literatura mostra a viabilidade da utilização de implantes de um estágio, cuja porção transmucosa é um prolongamento do corpo do implante com limite protético chanfrado que fica exposto no primeiro tempo cirúrgico.

A grande diferença entre estes sistemas relacionase com a localização das fendas entre os componentes secundários. Nos implantes de dois estágios, as fendas estarão localizadas no nível ou abaixo da crista óssea alveolar e nos tecidos moles ${ }^{16}$, facilitando a disseminação da contaminação bacteriana ${ }^{23}$.

Em nosso estudo pudemos observar que a extensão média da fenda foi de 3,89 $\pm 0,36 \mu \mathrm{m}$ (Figura $12 \mathrm{e}$ Tabela 1) nos implantes de dois estágios. Nossos resultados são condizentes com Piatelli, et $\mathrm{al}^{24}$, que encontraram variações entre $2 \mu \mathrm{m}$ e $9 \mu \mathrm{m}$ neste tipo de implante.

Nos implantes de um estágio cirúrgico, a fixação do intermediário será por travamento friccional tipo cone morse de $8^{\circ}$. Na Figura 9 pode ser observado o limite protético chanfrado e o limite da interface implante-intermediário. Nessa região aparece a fenda 
bastante irregular (Figura 11). Podemos especular que o travamento friccional poderá permitir uma adaptação íntima nas porções mais profundas do cone morse. Nestes implantes a extensão média da fenda foi de $3,98 \pm 1,29 \mu \mathrm{m}$ (Figura 13 e Tabela 1). Não houve diferença estatística significativa $(P>0,05)$ na extensão da fenda entre os sistemas (Tabela 1), entretanto, a discussão sobre sua localização nos parece pertinente.

Devemos salientar que no sistema de dois estágios, o intermediário é fixado no hexágono externo do implante por parafuso. O sistema de fixação por parafuso cria uma via de disseminação da contaminação do meio externo para o interno ${ }^{24,25}$. Estudos clínicos documentaram a presença de espécies microbianas na superfície interna e nos componentes protéticos dos implantes de dois estágios ${ }^{26,27}$. A fixação final da prótese parafusada parece criar outra condição clínica favorável à disseminação da contaminação.

O segundo procedimento cirúrgico dos implantes de dois estágios demanda um período de tempo de cicatrização adicional e pode prejudicar a estabilidade da mucosa perimplantar. Nesta etapa, a colocação dos cicatrizadores e dos componentes protéticos, pode interferir na qualidade da mucosa perimplantar ${ }^{28}$.

Para minimizar o efeito da contaminação bacteriana, as fendas deveriam apresentar pequena dimensão e ficar localizada no espaço do sulco perimplantar ou supragengival ${ }^{29}$. Nos implantes de um estágio, existe uma única fenda localizada entre o corpo do implante e a conexão protética que estará distante da crista óssea alveolar, próximo da margem gengival, preferencialmente dentro do sulco perimplantar. Nestes casos, a prótese será cimentada, selando a fenda e minimizando o risco de disseminação da contaminação.

\section{CONCLUSÃO}

Os tratamentos de superfície proporcionam diferentes padrões de rugosidade, e independente do sistema, ocorre formação de fenda entre os componentes dos implantes.

\footnotetext{
ABSTRACT

The aim of this study was to evaluate under scanning electron microscopy the characteristics of the implant surface and the gap between the components of two- and one-stage systems. Three twostage implants coated with RBM and three one-stage
}

implants coated with TPS were selected. In the twostage implants, the esthetic-cone abutments were adapted and screw tightened with $20 \mathrm{~N} / \mathrm{cm}$. In the one stage implants, solid abutments were adapted and torque tightened mechanical frictional with $30 \mathrm{~N} / \mathrm{cm}$. The specimens were mounted on stubs and analyzed under scanning electron microscopy. The gap in each implant was measured in four different points and repeated three times. The paired Student-t test was applied to detect the difference in the gap extension. The results showed that no significant differences $(\mathrm{P}$ $>0.05)$ were found regarding the gap extension between two- and one-stage systems and that the treatments produced different surface roughness.

UNITERMS: Dental implantation, endosseous.

\section{REFERÊNCIAS}

1- Adell R, Lekholm U, Röckler B, Bränemark PI. A 15-year study of osseointegrated implants in the treatment of edentulous jaw. Int J Oral Surg 1981; 10:387-416.

2- Albrektsson T, Dahle E, Enborm L. Osseointegrated Oral Implants: A Swedish multicenter study of 8139 consecutively inserted Nobelpharma implants. J Periodontol 1988; 59:287-96.

3- Branemark PI, Hansson BO, Adell R, Breine U, Lindström J, Hallén $\mathrm{O}$, et al. Osseointegrated implants in the treatment of the edentulous jaw. Experience from a 10-year period. Scand J Plast Reconstr Surg Hand Surg 1977; 11(Suppl. 16):1-132.

4- Cox JF, Zarb GA. The longitudinal clinical efficacy of osseointegrated dental implants: A 3-year report. Int J Oral Maxillofac Impl 1987; 2:91-100.

5- Schenk RK, Buser D. Osseointegration: a reality. Periodontology $20001998 ; 17: 22-35$.

6- Bränemark PI, Breine U, Adell R, Hansson O, Lindström J, Ohlsson Ä. Intra- osseous anchorage of dental prostheses. I. Experimental studies. Scand J Plast Reconstr Surg Hand Surg 1969; 3:81-100.

7- Schroeder A, Zypen E, Stich H, Sutter F. The reactions of bone, connective tissue and epithelium to endosteal implants with sprayed-titanium surfaces. J Maxillofac Surg 1981; 9:15-25.

8- Ellingsen JE. Surface conFigurations of dental implants. Periodontology 2000 1998; 17:36-46.

9- Frandsen PA, Christoffersen H, Madsen T. Holding power of different screws in the femoral head. A study in human cadaver hips. Acta Orthop Scand 1984; 55:349-51.

10- Wennerberg A, Albrektsson T, Andersson B, Krol JJ. A histomorphometric and removal torque study on screw-shaped titanium implants with three different surface topographies. Clin Oral Impl Res 1995; 6:24-30. 
11-Wilke HJ, Claes L, Steinemann S. The influence of various titanium surfaces on the interface shear strength between implants and bone. Advances Biomaterials 1990; 9:309-14.

12- Buser D, Schenk RK, Steinemann S, Fiorellini JP, Fox CH, Stich H. Influence of surface characteristics on bone integration of titanium implants. A histomorphometric study in miniature pigs. J Biomed Mat Res 1991; 25:889-902.

13- Jemt T, Laney W, Harris D, Henry P, Krogh R, Polizzi G, et al. Hermann I. Osseointegrated implants for single-tooth replacement: A 1-year report from a multicenter prospective study. Int J Oral Maxillofac Implants 1991; 6:29-36.

14- Laney W, Jemt T, Harris D, Henry P, Krogh R, Polizzi G, et al. Hermann I. Osseointegrated implants for single-tooth replacement: Progress report from a multicenter prospective study after 3 years. Int J Oral Maxillofac Implants 1994; 9:49-54.

15-Garber DA, Salama H, Salama MA. Two-stage versus onestage. Is there really a controversy? J Periodontol 2001; 72:417424.

16- Hermann JS, Cochran DL, Nummikoski PV, Buser D. Crestal bone changes around titanium implants. A radiographic evaluation of unloaded nonsubmerged and submerged implants in the canine mandible. J Periodontol 1997; 68:1117-30.

17-Listgarten MA, Lang NP, Schroeder HE, Schroeder A. Periodontal tissues and their counterparts around endosseous implants. Clin Oral Impl Res 1991; 2:1-19.

18-Suttler F, Schroeder A, Buser D. The new concept of ITI hollow-cylinder and hollow-screw implants. 1. Engineering and design. Int J Oral Maxillofac Implants 1988; 3:161-172.

19-Carlsson L, Röstlund T, Albrektsson B, Albrektsson T. Removal torques for polished and rough titanium implants. Int $\mathbf{J}$ Oral Maxillofac Surg 1988; 3: 21-4.

20-Carr AB, Beals DW, Larsen PE. Reverse-torque failure of screw-shaped implants in baboons after 6 months of healing. Int J Oral Maxillofac Implants 1997; 12:598-603.

21 - Buser D, Mericske-Stern R, Bernard JP, Behneke A, Behneke $\mathrm{N}$, Hirt HP, et al. Long-term evaluation of non-submerged ITI implants. I. An 8-years life table analysis of a prospective multicenter study with 2359 implants. Clin Oral Impl Res 1997; 8:16172 .

22- Kasemo B, Lausmaa J. Biomaterial and implant surfaces: on the role of cleanliness contamination and preparation procedures. J Biomed Mater Res 1988; 22 (Suppl. A2):145-58.

23-Hermann JS, Schoolfield JD, Schenk R, Buser D, Cochran DL. Influence of the size of the microgap on crestal bone changes around titanium implants. A histometric evaluation of unloaded non-submerged implants in the canine mandible. J Periodontol 2001; 72:1372-83

24- Piattelli A, Scarano A, Paolantonio M, Assenza B, Leghissa GC, Bonaventura G, et al. R. Fluids and microbial penetration in the internal part of cement-retained versus screw-retained implantabutment connections. J Periodontol 2001; 72:1146-50.
25- Callan D, O'Mahony A, Cobb CM. Loss of crestal bone around dental implants: a retrospective study. Implant Dent 1998; 7:25865 .

26- Jansen VK, Conrads G, Richter EJ. Microbial leakage and marginal fit of the implant-abutment interface. Int J Oral Maxillofac Implants 1997; 12:527-40.

27- O'Mahony A, MacNeill SR, Cobb CM. Design features that may influence bacterial plaque retention: A retrospective analysis of failed implants. Quintessence Int 2000; 31:249-56.

28- Joly JC, Lima AFM. Comparação entre sistemas de implantes de um e dois estágios - relato de casos. J Bras Implantodontia 2001; 7: 8-11.

29- Persson LG, Lekholm A, Dahlen G, Lindhe J. Bacterial colonization on internal surfaces of Bränemark system implant components. Clin Oral Impl Res 1996; 7:90-95.

Recebido para publicação em: 03/10/2002

Aceito após reformulações em: 20/03/2003

Endereço para correspondência:

Faculdade de Odontologia de Piracicaba da

Universidade Estadual de Campinas

Prof. Dr. Antonio Fernando Martorelli de Lima

Avenida Limeira, 901 - Areião

Piracicaba - SP

CEP: 13414-900

Telefone: (19) 34125299

FAX: (19) 34265730 / 34125218

e-mail: afmlima@fop.unicamp.br

joly@linkway.com.br 